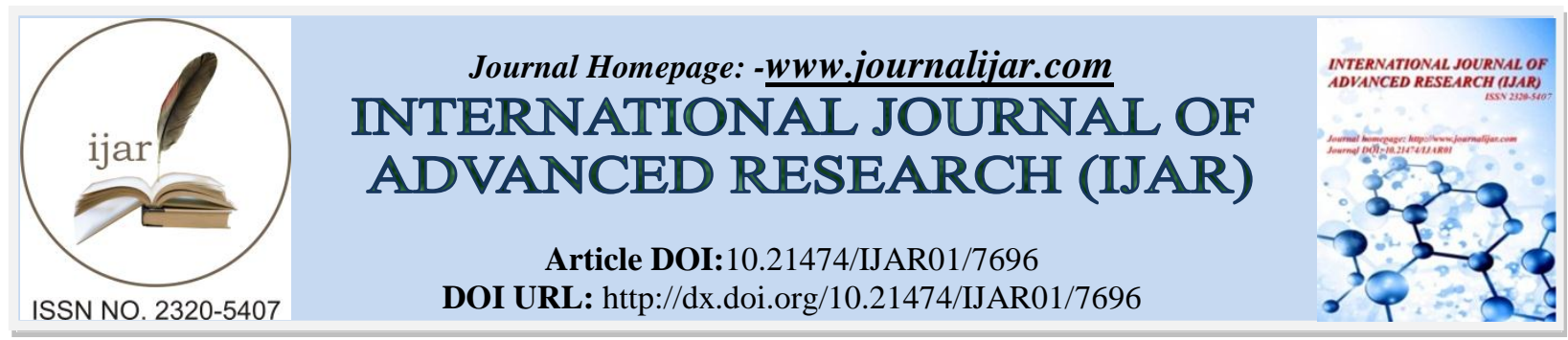

RESEARCH ARTICLE

\title{
THE HYPOTHETICAL ROLE OF ZINC, MAGNESIUM, SELENIUM AND CAROTENOIDS IN THE PREVENTION OF PROSTATE CANCER: A CLINICAL BASIC STUDY.
}

\author{
Saeed Hussein Assi and Ahmed Ibrahim Jessim. \\ Ministry of Science and Technology, Treatment and disposal of chemical, biological and, military hazardous wastes, \\ Center for research and evaluation, Baghdad - Iraq.
}

\section{Manuscript Info}

\section{Manuscript History}

Received: 19 July 2018

Final Accepted: 25 August 2018

Published: September 2018

Keywords:-

Cancer, Zinc (Zn), Magnesium (Mg), Selenium (Se), $\beta$-Carotene, Lycopene, Carotenoids.

\section{Abstract}

This study aimed to estimate an essential traces elements levels of Zinc $(\mathrm{Zn})$, Magnesium $(\mathrm{Mg})$, and Selenium $(\mathrm{Se})$ also $\beta$-carotene and Lycopene from carotenoids to evaluate their roles in protecting of prostate gland cells from various oxidative processes in order to protect DNA from mutation which results in the accidence of prostate cancer. the samples of the study are selected from the community were they suffering from prostate cancer were taken randomly from 15 of men, suffering from prostate and 13persons healthy men, aged 45 to 70 years old. Results showed a highly significant which decreased when $\mathrm{p}<$ 0.001 in all level of $\mathrm{Zn}, \mathrm{Mg}$, Se $\beta$-carotene, Lycopene

Copy Right, IJAR, 2018,. All rights reserved.

\section{Introduction:-}

Prostate cancer is the most common cancer and the second leading cause of death in American men (Jamal et al., 2009). It is estimated that in 1997, there will be 209000 new prostate cancer cases and 41800 deaths from prostate cancer. Dietary factors which have been investigated include carotenoids such as beta-carotene, Lycopene and the essential trace elements ( $\mathrm{Zn}, \mathrm{Mg}$, and $\mathrm{Se}$ ). The association of prostate cancer with the intake of certain dietary nutrients suggests that they may be useful preventive agents. The high concentration of zinc in the prostate suggests that $(\mathrm{Zn})$ may play a role in prostate health. The concentration of $(\mathrm{Zn})$ in the prostate is higher than that of any other soft tissue in the body (Zaichick et al., 1997). Magnesium is the second most abundant intracellularcation in the body, involved in over 300 biological activities (Iseri and French, 1984). Chronic inflammation may also play a key role in the progression from normal tissue to Prostatic Intraepithelial Neoplasia (PIN) and prostate cancer (De Marzo et al., 2007). Dietary (Se) has been inversely associated with the risk of cancer since the 1960s, the interest in selenium as a nutrient with potential preventive effects against prostate cancer was heightened in the mid-1990s, after reports from the Nutritional Prevention of Cancer Trial showed that men who received $200 \mu \mathrm{g}$ selenium had a significantly reduced risk of this disease (Combs, 2004).

The Chemopreventive effects of selenium may be due to its roles in cell cycle arrest, decreasing proliferation, inducing apoptosis, facilitating DNA repair by activation of p53, disruption of androgen receptor signaling, and being a key component of selenium coenzymes (Dong et al., 2004; Driscoll and Copeland, 2003), which incorporate selenium as selenocysteine, an infrequently occurring amino acid, into their active center (Jiang et al., 2001). The research emphasizing the biology of carotenoids was initiated after Peto et al., 1981) suggested that $\beta$-carotene might be the primary anticancer agent in fruits and vegetables (Menter et al., 2000). Numerous studies have shown 
that a high intake of carotenoid-rich fruit and vegetables or high blood levels of $\beta$-carotene are associated with a reduced risk of cancer at a number of common sites, such as prostate, lung, and stomach (Venkateswarm, 2002).

Lycopene is known well as a carotenoid which is an acyclic isomer of beta-carotene and has no vitamin A activity (Zhong and Oberley, 2001). It is a highly unsaturated, straight chain hydrocarbon containing 11 conjugated and 2 non- conjugated double bonds. Lycopene has antioxidant properties. Several studies have indicated the Lycopene is an effective antioxidant and free radical scavenger (Dong et al., 2003; Rao and Agrawal, 1999).

\section{Materials and Methods:-}

\section{Sampling}

Method of collecting blood samples from patients with prostate cancer.

Blood samples were collected from patients with prostate cancer and who were in Al-Amel international hospital for atomic radioactive treatment, after checking the name of the patient, the number of his profile and conducted analyses. Before collectingthe blood sample, the hand of patients are hands were lifted up gently and attached by a tourniquet above the elbow hard enough until it becomes a clear vein, then cleaned well by alcohol and wipe it with cotton until it dries and the needle inserted into the vein at an angle of $45^{\circ}$ and gently pull the syringe handle to pull the blood smoothly, after that, separately blood transferred from syringes to the test tubes which they have not any anticoagulants such as heparin for the required tests, finally all wanted information's of the patientwrote on the test tubes (name, number of profile and room number).

\section{Serum preparation}

All obtained samples of blood are centrifuged at $3500 \mathrm{rpm}$ along five minutes to get upper nature yellow layer which is blood serum

\section{Chemical Reagents}

$\beta$-Carotene, and Lycopene from (Sigma, USA), Zinc, Magnesium, and Selenium from (Merck, Germany), $95 \%$ Nhexane and ethyl acetate (fluke, Swiss) for high-performance liquid chromatography (HPLC), 99.8\% ethyl alcohol (fluke, Swiss) were used to prove this study.

\section{Methods:-}

\section{Determination of Serum Magnesium}

For determination of total magnesium in blood serum is determined by utilizing atomic absorption spectrophotometer via the Flame method. To prepare the standard solution in the range of $(0.1$ to $1 \mu \mathrm{g} / \mathrm{ml})$ from a standard solution of. AA 7000 Shimadzu atomic absorption spectrophotometer was used. (Iseri and French, 1984).

\section{Determination of Serum Zinc}

Determination of total zinc in blood serum was determined by utilizing atomic absorption spectrophotometer (flame method). Set of standard solution ranging $(0.05$ to $0.8 \mu \mathrm{g} / \mathrm{ml}) \mathrm{Zn}$ was prepared. AA 7000 Shimadzu atomic absorption spectrophotometer was used (Zaichick, et al., 1997).

Determination of serum selenium

Determination of total selenium in blood serum was determined by utilizing atomic absorption spectrophotometer (flameless method). Set of standard solution ranging (10 to $110 \mathrm{ng} / \mathrm{ml}$ ) was prepared. AA 7000 Shimadzu atomic absorption spectrophotometer was used. (Combs, 2004).

\section{Assessment of serum $\beta$ - Carotene and Lycopene}

$\beta$ - Carotene, and Lycopene were measured simultaneously by high-performance liquid chromatography (HPLC) in two groups of patients: 15 men with prostate cancer and 13 healthy men. Blood samples were collected from patients and healthy individuals to measure total serum $\beta$-Carotene and Lycopene. Blood was collected via venipuncture, all tubes were protected from light, allowed to clot, centrifuged at $3000 \mathrm{rpm}$ for $10 \mathrm{~min}$, and then stored at $-30 \mathrm{C}^{\mathrm{o}}$ until thawed for analyses by high-performance liquid chromatography HPLC. $(454,450 \mathrm{~nm})$. UFLC Shimadzu HPLC was used (Kryuk et al., 2003). 


\section{Statistical Analysis}

Data were presented as the mean \pm standard deviation (SD). The statistical analysis of data was done by using Excel program and SPSS program (statistical package for social Science Version 11), data between the groups were compared with Student's $t$-test for continuous variables and chi-square t-test for continuous variables. MannWhitney's U-test was used for variables without normal distribution. A two-tailed P-value of $<0.05$ was considered significant (George, 1981).

\section{Results and Discussion:-}

Resultsofthepresentstudy showed high significantlydecreased( $\mathrm{P}<0.001)$ inlevelsofZinc $\mathrm{Zn}$, Magnesium $\mathrm{Mg}$, Selenium Se, Beta-carotene, and Lycopene in patients with cancer group compared to control group as shown.

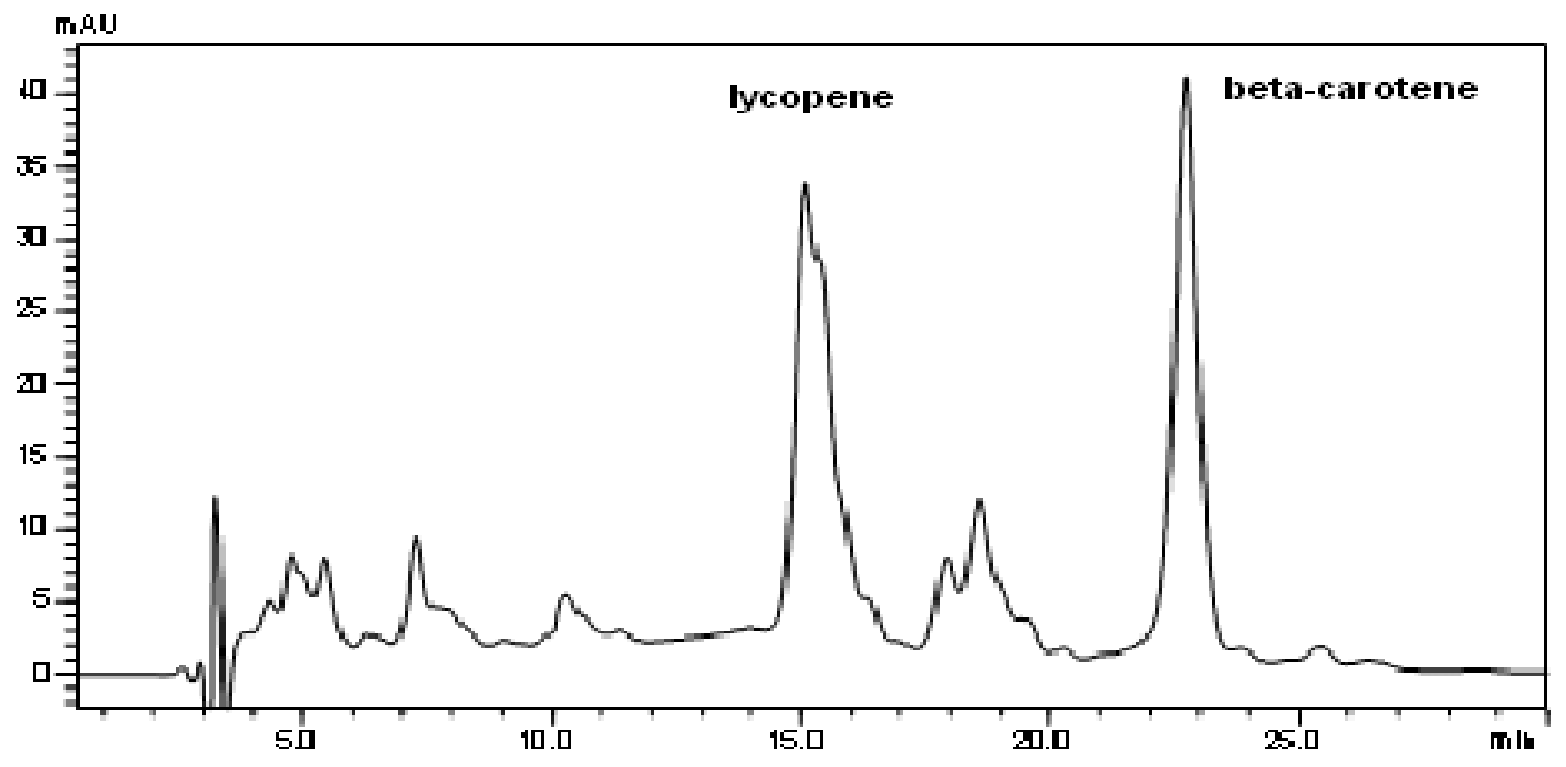

Figure1:-Chromatogram lycopene and beta-carotene HPLC Technique

Table1;-Serum levels of Zinc, Magnesium, Selenium and $\beta$-carotene in men with prostate cancer and healthy men groups.

\begin{tabular}{|l|l|l|l|}
\hline Parameters & $\begin{array}{l}\text { Men with prostate cancer } \\
\text { No.15 }\end{array}$ & $\begin{array}{l}\text { Healthy men (control group) } \\
\text { No.=13 }\end{array}$ & P value \\
\hline Zinc $\mu \mathrm{g} / \mathrm{ml}$ & $0.65 \pm 0.09$ & $1.00 \pm 0.08$ & $\mathrm{p}<0.001$ \\
\hline Magnesium $\mu \mathrm{g} / \mathrm{ml}$ & $10.32 \pm 1.22$ & $24.00 \pm 2.05$ & $\mathrm{p}<0.001$ \\
\hline Selenium $\mu \mathrm{g} / \mathrm{ml}$ & $73.50 \pm 8.20$ & $115.00 \pm 15.6$ & $\mathrm{p}<0.001$ \\
\hline$\beta$ - Carotene $\mu \mathrm{g} / \mathrm{ml}$ & $0.12 \pm 0.02$ & $0.32 \pm 0.07$ & $\mathrm{p}<0.001$ \\
\hline Lycopene $\mathrm{g} / \mathrm{ml}$ & $0.09 \pm 0.01$ & $0.32 \pm 0.07$ & $\mathrm{p}<0.001$ \\
\hline
\end{tabular}

The present study was showed Table (1) Zinc, Magnesium, Selenium, $\beta$ - carotene, and Lycopene in patients with prostate cancer group compared to control group as shown in figure (1) showed the chromatogram of $\beta$ - carotene, and Lycopene HPLC device. The epidemiology of prostate cancer is complex, with few established risk factors; those most established are family history, age, country, race, and testosterone deficiency. The association of prostate cancer with intake of certain dietary nutrients suggests that they may be useful for preventing agents. An obtained of zinc concentration in healthy and patient groups which are shown in the table (1) showed highly significant differences in serum zinc level, decreased $(\mathrm{p}<0.001)$, the concentration of zinc is so low inpatient group as compared with that in control group. The results obtained in this study are so similar to those published in the literature (Zaichick et al., 1997; Peto et al., 1981; Wang and Russell, 1999).In prostate cancer, decreased zinc levels areconsistently observedinmalignanttissuesamplesfromdifferentpopulations and atvariousstagesof malignancy (Goel 
and Sankkhwar, 2006).Analysisof malignantprostatetissues showeda60$70 \%$ reductionofzinclevelsincomparisontothoseofthenormalperipheral zonetissues. From table (1) we can see results of serum magnesium levels of patients and healthy groups. The results revealed high differences between both groups, decreased $(\mathrm{p}<0.001)$, our results indicate that serum magnesium levels decrease significantly during prostate cancer incidence. These results are in agreement with the data of (Iseri and French, 1984). The role of magnesium in cancer formation is complex. Numerous studies have focused on the effect of magnesium deficiency on tumour incidence, where an unbalanced magnesium homeostasis is either magnesium deficiency or supplementation can affect the progression of existing tumours. (Vartsky, et al., 2003; Wolf et al., 2007). It has been found that magnesium could impact carcinogenesis by two mechanisms, first, magnesium deficiency in association with inflammation, second, magnesium deficiency might be an association with increased levels of free radicals. Both inflammatory mediators and free radicals might lead to oxidative DNA damage and thereby cancer formation. Magnesium is also known to stabilize the structure of nucleic acids and is a vital co-factor of enzymes involved in DNA replication, repair and gene expression. DNA repair mechanisms are responsible for genomic stability and fidelity, thus any magnesium deficiency may contribute to defects in these systems and the appearance of DNA mutations (Castiglioni and Maier, 2011). Accumulation of genomic alterations may thereby lead to tumor-genesis (Anastassopoulou and Theophanides, 2002). Several studies have shown an increased cancer rate in regions with low magnesium levels in soil and drinking water and the same for selenium. Selenium is an essential nutrient with a recommended daily allowance of $70 \mu \mathrm{g}$ in men. The variable distribution of Se in soil and foods produce geographical regions and populations with varying Se status as the epidemiology suggests that individuals with low (Se) levels are at higher risk of cancer, it appears that (Se) supplementation decreases the incidence of prostate cancer in men. Because of its effects on DNA repair, apoptosis and the endocrine and immune systems as well as other mechanisms, including its antioxidant properties. (Se) might play a role in the prevention of cancer. Epidemiological studies have suggested an inverse association between selenium status and the risk of prostate cancer specimens. (Denrt et al., 2011).

The mean $\pm \mathrm{SD}$ for control group is $115.00 \pm 15.6 \mathrm{ng} / \mathrm{ml}, 0.32 \pm 0.07 \mu \mathrm{g} / \mathrm{ml}$, and $0.32 \mu \mathrm{g} / \mathrm{ml}, 0.32 \pm 0.07 \mu \mathrm{g} / \mathrm{ml}$ for Se, $\beta$-carotene and Lycopene respectively. High significant differences were found decreased $(p<0.001)$ for all variables in the patient group compared with the control group. These results proved the possible relationship between low levels of mentioned parameters and risk factors of prostate cancer incidents. The obtained results are in agreement with those of others who also observed declines in serum Se, beta-carotene and lycopene values (Combs, 2004; Rao and Agrwal, 1999; Peto et al., 1981; Renty and Leslie 2007).

The fact that LDL is a major transporter of $\beta$-carotene and lycopene in the circulation and that these carotenoids have the capacity to trap peroxyl radicals and quench singlet oxygen lends support to this hypothesis, $\beta$-carotene is a scavenger of peroxyl radicals, especially at low oxygen tension. This activity may be also exhibited by others carotenoids. The interaction of carotenoids with peroxyl radicals may proceed via an unstable $\beta$-carotene adduct radical. Carotenoid adduct radicals have been shown to be highly resonance stabilized and are predicted to be relatively unreactive. They may further undergo decay to generate unradical products and may terminate radical reactions by binding to the attacking free radicals. Carotenoids act as antioxidants by reacting more rapidly with peroxyl radicals than do unsaturated acyl chains. In this process, arytenoids are destroyed (Renty and Leslie 2007). Serum levels of Lycopene in prostate cancer patients were significantly lower than their age-matched controls (Rao et al., 1999). It is hypothesized that prostate cancer patients perhaps lack the ability to isomerise dietary Lycopene and therefore do not absorb it efficiently. Our results are agreements with all mentioned studies in above

\section{Conclusion:-}

The present study indicates that $\mathrm{Zn}, \mathrm{Mg}$, and Se are minerals which play important role in the prevention of prostate cancer in males in addition to some carotenoids such as beta-carotene which play the same role. It is well recommended that dietary intake of these nutrients as supplementation a day to take advantage of their antioxidant properties for the prevention of prostate cancer.

\section{Acknowledgement:-}

We thank all people to their kind help to accomplish this research. 


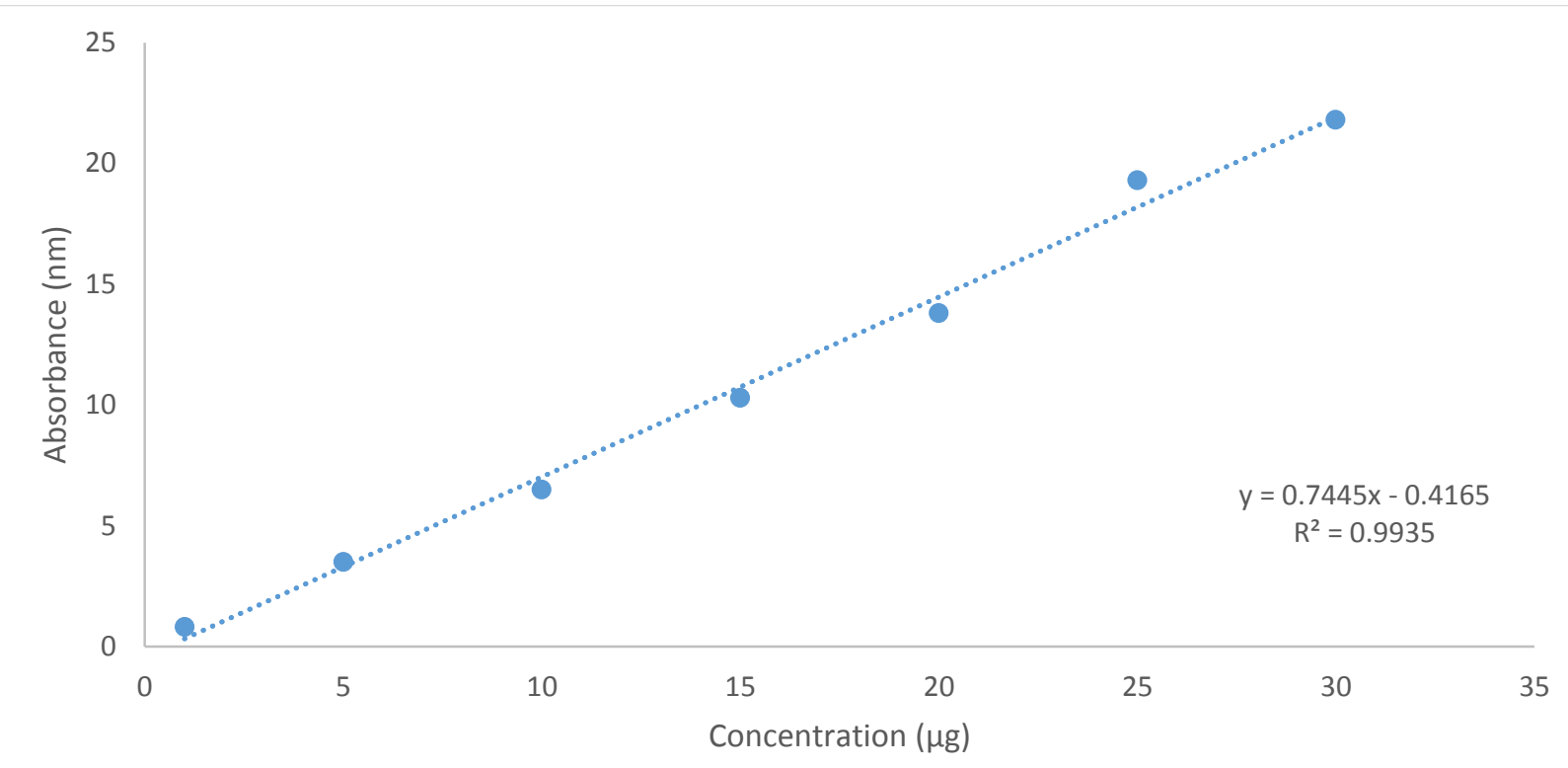

Figure 2:-Calibration curve of Magnesium (Mg)

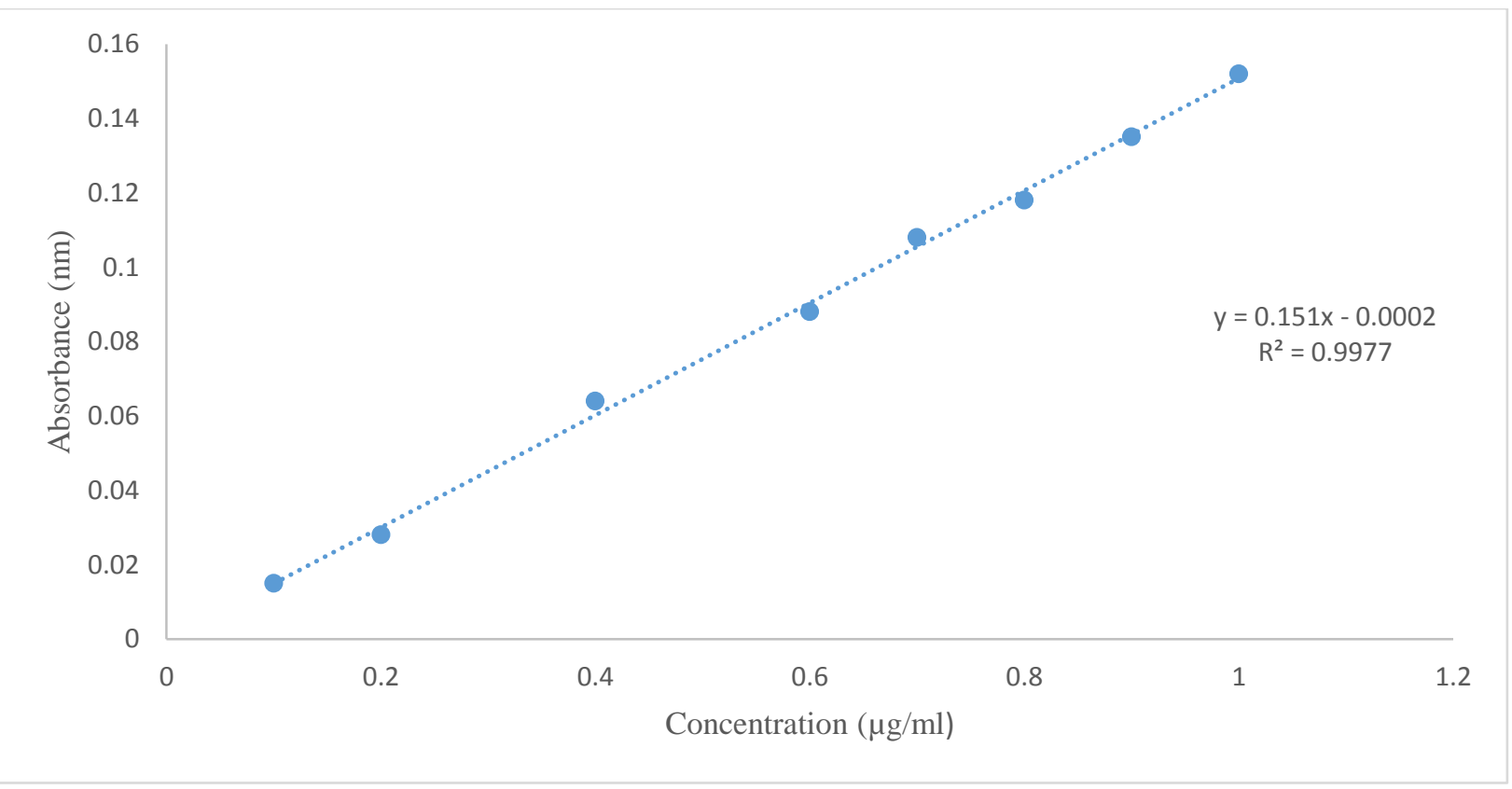

Figure 3:-Calibration curve of Zinc (Zn) 


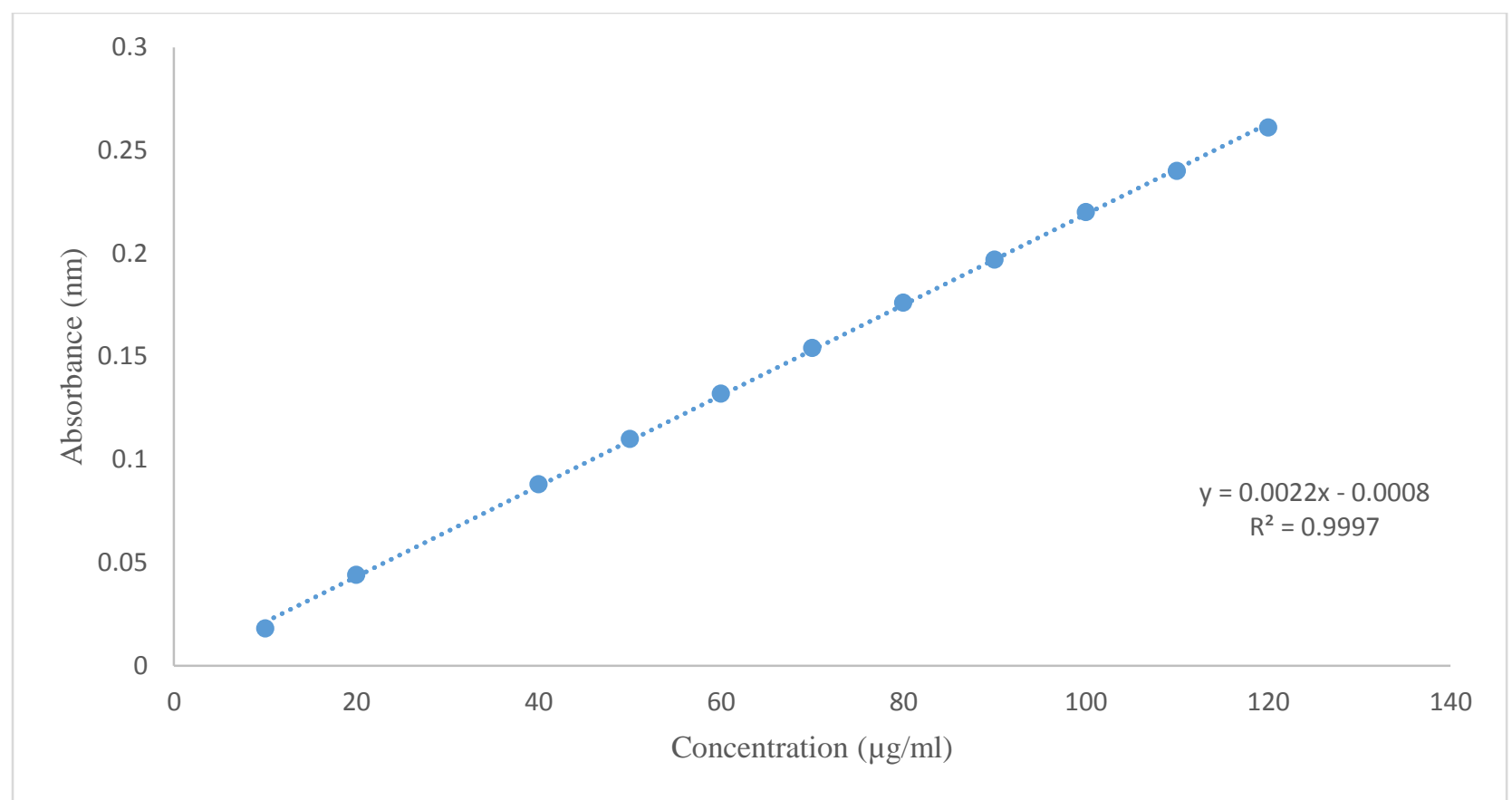

Figure 4:-Calibration curve of Selenium (Se)

\section{References:-}

1. Jamal, A., Siegel R., Ward E., Hao Y., Xu J., Thun, M.J.,m 2009. Cancer statistics, CA Cancer J. Clin. 59, 225249

2. Zaichick, V., Sviridova, T.V., Zaichick, S.V., 1997. Zinc in the human prostate gland: normal, hyperplastic and cancerous. IntUrolNephrol, 29, 565-74

3. Iseri, LT., French, J.H. 1984. Magnesium: natures' physiologic calcium blocker. Am Heart. J 108, 188-193

4. De Marzo, A.M., Platz, E.A., Sutcliffe, S., Xu, J., Gronberg, H., Darke, C.G., Nakai, Y., Isaacs, W.B., Nelson.W.G., 2007. Inflammation in prostate carcinogenesis. Nat Rev Cancer. 7, 256-269

5. Combs, G.F., 2004. Status of selenium in prostate cancer prevention. Br. J. Cancer. 91, 195-199

6. Dong, Y., Lee, S.O., Zhang, H., Marshall, J., Gao A.C., Ip, C. 2004. Prostate-specific antigen expression is down-regulated by selenium through disruption of androgen receptor signalling. Cancer Res. 64, 19-22

7. Driscoll D.M. Copeland, P.R. 2003. Mechanism and regulation of selenoprotein synthesis. Annu Rev Nutr 23, $17-40$

8. Jiang, C., Wang, Z., Ganther, H., Lu, J. 2001. Caspases as key executors of methyl selenium-induced apoptosis (anoikis) of DU-145 prostate cancer cells. Cancer Res. 61:3062-70

9. Menter, D.G., Sabichi, A.L., Lippman, S.M., Selenium effects on prostate cell growth. Cancer Epidemiol Biomarkers Prev.9, 1171-1182

10. Venkateswaran, V., Klotz, L.H., Fleshner, N.E., 2002. Selenium modulation of cell proliferation and cell cycle biomarkers in human prostate carcinoma cell lines. Cancer Res. 62:2540-2545

11. Zhong, W., Oberley, T.D., 2001. Redox-mediated effects of selenium on apoptosis and cell cycle in the LNCaP human prostate cancer cell line. Cancer Res. 61:7071-7078

12. Dong, Y., Zhang, H., Hawthorn, L., Ganther, H.E., Ip, C., 2003. Delineation of the molecular basis for selenium-induced growth arrest in human prostate cancer cells by oligonucleotide array. Cancer Res. 63, 52-59

13. Rao, A.V. Agarwal, S., 1999. Role of lycopene as antioxidant-carotenoid in the prevention of chronic disease: a review. Nutr Res. 19, 305-323

14. Kryukov, G.V, Castellano, S., Novoselov, S.V., Lobanov, A.V., Zehtab, O., Guigó, R., Gladyshev, V.N., 2003. Characterization of mammalian selenoproteomes. Science. PubMed. 300:1439-1443

15. George, A.F., 1981. Statistical Analysis in Psychology and Education, $5^{\text {th }}$ Ed. McGraw- Hill Book Company.

16. Peto, R., Doll, R., Buckley, J.D., Sporn, M.B., 1981. Can Dietary beta-carotene Materially Reduce Human Cancer Rates? Nature; 290, 201-208 
17. Wang, X.D., Russell, R.M., 1999. Procarcinogenic and anticarcinogenic effects of beta-carotene. Nutr. Rev. 57, 263-272

18. Goel, T., Sankkhwar, S.N., 2006. Comparative study of zinc levels in benign and malignant lesions of the prostate. Scand J UrolNephrol. 40, 108-112

19. Vartsky,D., Shilstein, S., Bercovich, A., Huszar, M., Breskin, A., Chechik, R., KorotinskyS., S.D., Malnick,M.E., 2003.Prostaticzincandprostate-specificantigen:An experimentalevaluationoftheircombineddiagnosticvalue.J.Urol, 170, 2258-2262

20. Wolf, F.I., Maier, J.A.M., Nasulewicz, A., Feillet-Coudray, M., Simonacci, C., Mazur, A. Cittadini, A., 2007. Magnesium and neoplasia: From carcinogenesis to tumour growth and progression or treatment. Arch BiochemBiophys. 458, 24-32

21. Castiglioni, S., Maier, J.A.M., 2011. Magnesium and cancer: a dangerous liaison. Magnes Res 24, S92-S100

22. Anastassopoulou, J., Theophanides, T., 2002. Magnesium- DNA interactions and the possible relation of magnesium to carcinogenesis. Irradiation and free radicals. Crit Rev OncolHematol. 42, 79-91

23. Dent, G.M., Zwahlen, M., Brinkman, M., Vinceti, M., Zeegers, M.P., Horneber, M., 2011. Selenium for preventing cancer. Cochrane Database SystRen: 11: (5):CD005195.

24. Renty, B.F. Leslie, C.C., 2007. Zinc as antitumour agent in prostate cancer and in other cancers. 463, 211-217

25. Rao, A.V., Fleshner N., Agarwal, S. 1999. Serum and tissue lycopene and biomarkers of oxidation in prostate cancer patients: a case-control study. Nutr cancer 33, 159-16. 